\title{
SMA in mitigation of extreme loads in civil engineering: Study of their application in a realistic steel portico
}

\author{
Vicenç Torra ${ }^{1, a}$,Antonio Isalgue ${ }^{1}$, Carlota Auguet $^{1}$, \\ Guillem Carreras ${ }^{1}$, Fabio Casciati ${ }^{2, b}$, Francisco C. Lovey ${ }^{3, c}$, \\ Patrick Terriault ${ }^{4, d}$
}

${ }^{1}$ CIRG-Applied Physics, ETSECCPB, Polytechnical University of Catalonia, Barcelona, Catalonia, E-08034 Spain

${ }^{2}$ Department of Structural Mechanics, University of Pavia, Via Ferrata 1, I-27100 Pavia, Italia

${ }^{3}$ Centro Atomico Bariloche (CAB-IB) Bariloche, 8400 Argentina

${ }^{4}$ LAMSI, ETS, Université de Québec, H3C 1K3 Montréal, Ca.

a vtorra@fa.upc.edu, ${ }^{b}$ fabio@dipmec.unipv.it, clovey@cab.cnea.gov.ar, ${ }^{d}$ patrick.terriault@etsmtl.ca

Keywords: Shape Memory Alloys, damping, passive systems, earthquake mitigation, fatigue-life.

Abstract. Guaranteeing the use of Shape Memory Alloys (SMA) in mitigation of extreme load effects requires a deep study of the SMA behavior according to the specific requirements of the applications in damping. The damper was defined according the expected requirements (length of SMA and number of SMA wires). It is applied to two types of alloys (CuAlBe and NiTi) in the diagonals of a realistic steel portico $(2.47 \mathrm{~m} \mathrm{x} 4.10 \mathrm{~m})$. The measurements establish that the used SMA reduces the oscillation amplitude to a less than a half.

\section{Introduction}

The use of Shape Memory Alloys (SMA) in mitigation of extreme load effects requires appropriateness of the SMA behavior according to the specific requirements of the applications in damping. In particular, it is necessary: 1) A guaranteed behavior of the SMA material for 10002000 cycles of working oscillations without fatigue and/or fracture. 2) An invariable behavior after several decades of summer - winter external temperature oscillations. 3) That the length of the damper remains constant when works. Two types of alloys (CuAlBe and NiTi) were applied to a steel portico of reasonable realistic dimensions.

The steel portico was situated in a trolley. The carriage was activated by a hydraulic piston. The inverted U-shape of the portico made by three HEB elements, the pillars of $2.47 \mathrm{~m}$ length and the beam with $4.10 \mathrm{~m}$ length. The experimental study was realized for different loads on the portico (up to $20 \mathrm{kN}$ ). As expected, the results establish a decrease of the portico resonance frequency with the load and positive damping effects of the SMA. The experimental measurements establish that the used SMA reduces the oscillation amplitude to a less than a half with minor effects in the frequencies of the structure.

When SMA is used as a damper for Civil Engineering, it needs to be reliable for each expected "Richter" earthquake requirement. All applications require a deep particular study of their specific requirements. Then, when SMA will be used in mitigation of earthquake (EQ) effects need to be guaranteed for their appropriate requirements. It means, it is necessary to appropriate knowledge of the next conditions particularized for earthquakes [1]:

$\mathrm{A}_{\mathrm{EQ}}$ : oscillation's interval (earthquake + replica's): 4 to 6 minutes

The fatigue / fracture-life of the material needs to be, at least, that overcomes 1000 working cycles (the length of time of one earthquake is close to 1 minute plus $\mathrm{N}$ aftershocks or replicas represent $(1+\mathrm{N}$ minutes). With a frequency oscillation of $1 \mathrm{~Hz}$ a satisfactory behavior up to 1000 working cycles was required.

$\mathrm{B}_{\mathrm{EQ}}$ : time scale, for instance, several decades between quakes. 
It's necessary that the eventual time effects induced by diffusion (i.e., by precipitate accretion) or by evolution of the atomic order (i.e., by vacancy flow) was avoided or well quantitatively determined [2]

$\mathrm{C}_{\mathrm{EQ}}$ : high number of daily and yearly (summer-winter) temperature wave.

The action of several decades of summer-winter yearly temperature (inside the house) effects would not modify the required properties of the SMA or their working capacity.

\section{$D_{\mathrm{EQ}}$ : the damper length need to remain invariant}

The effects associated to progressive deformation on cycling need to be minimized or avoided via the appropriate previous training and/or thermo-mechanical treatment.

$\mathrm{E}_{\mathrm{EQ}}$ : self-heating not relevant or well determined.

The self-heating needs to be evaluated or quantified. The heat dissipated by the hysteresis, or the Hysteretic Work (HW), goes abroad by transmission to surroundings but other part increases the temperature of the specimen. The effect, sensitive at cycling frequency, increases the stress due to the Clausius-Clapeyron thermodynamic equation.

$\mathrm{F}_{\mathrm{EQ}}$ : dampers with re-centering availabilities were positive.

The pseudo-elasticity with their transformation and retransformation processes recovers their initial position. On cycling with SMA dampers the structure oscillates with reduced amplitude and recovers the original position or re-centering availability.

This paper is focused in the fracture life for $\mathrm{NiTi}$, in the realistic structure built (a $2.47 \mathrm{~m} \mathrm{x} 4.10 \mathrm{~m}$ steel portico) and in the experimental results obtained inducing oscillations free and with SMA dampers.

\section{Experimental}

The experimental analysis is devoted to SMA alloys. The CuAlBe alloy [3] was furnished, firstly, by the research centre of Trefimetaux, France (in 2003 and 2004) and later by NIMESIS, France in 2005-2007 with similar original casts. The studied alloy were wires produced from the cast AH140 (Trefimetaux), their reference data are: $\mathrm{Ms}=255 \mathrm{~K} ; \mathrm{Mf}=226 \mathrm{~K} ; \mathrm{As}=253 \mathrm{~K}$; $\mathrm{Af}=275 \mathrm{~K}$. The corresponding chemical composition in mass per cent reads: $\mathrm{Al}=11.8 ; \mathrm{Be}=0.5$; $\mathrm{Cu}=87.7$. The cast $\mathrm{A} 140$ of $\mathrm{CuAlBe}$ shows a Clausius-Clapeyron coefficient near $2.2 \mathrm{MPa} / \mathrm{K}$ [4]. Several lengths of the wires are used in testing, usually with a diameter of $3.4 \mathrm{~mm} \mathrm{[5].} \mathrm{The} \mathrm{CuAlBe}$ alloy arrives from furnisher after direct extrusion (at $1173 \mathrm{~K}$ ) of the wires with cooling by a flow current of water at room temperature. The alloy appears in a mixture of $\alpha+\beta$ phases. A progressive and permanent residual deformation, partially due to SMA creep and also because of some plastic deformation of $\alpha$ phase, appears under stress. Practical application of the alloy requires a homogenization process and some thermo-mechanical treatment [1].

The NiTi wires have been furnished by Special Metals (actually SAES Getters) in pseudo-elastic state. After homogenization of ten minutes at $1093 \mathrm{~K}$, the wires of $2.46 \mathrm{~mm}$ of diameter have been trained by 20 cycles with a maximal deformation of $8 \%$ before using as a damper (Fig. 1 left).

\section{Fatigue - fracture levels of CuAlBe and NiTi}

The fracture level of CuAlBe alloy for their application to damping of earthquakes has been studied for different homogenization time (time at $1093 \mathrm{~K}$ ) ensuring that the samples are completely in parent phase. The CuAlBe alloy, after minor training, can be used in damping of structures for maximal oscillation amplitudes under $2.3-3.0 \%$. At this level, the material permits more than 2000 working cycles previous to fracture [1].

The requirements for stayed cables require deeper analysis of fracture levels, and, also good resistance to wetting an associate oxidation. In these conditions NiTi was the appropriate alloy (see Fig. 1). Using net deformations under $2 \%$ the number of cycles overcomes 4 million of working cycles with reduced energy. For samples near $100 \mathrm{~mm}$ length the dissipated energy remains near 0.1 $\mathrm{J} /$ cycle. For expected cable displacements near $\pm 40 \mathrm{~mm}$, the required SMA length for $1 \%$ transformation overcomes $4 \mathrm{~m}$ or the dissipated energy overcomes $4 \mathrm{~J} /$ cycle. With this idea, it is possible to install one straight line of SMA wires linking 2 or 3 consecutive cables between them. 
The Fig. 1 right shows the experimental results for the number of working cycles using NiTi wires of $2.46 \mathrm{~mm}$ of diameter. A relatively relevant series of measurements was realized to determine the fracture-life as a function of the maximal external stress. Reduction of the cycling amplitude to near or under $200 \mathrm{MPa}$ increases the fracture life. The comparison between Fig. 1 left and right establishes that, for earthquake mitigation, the fracture in NiTi overcomes 5000 working cycles for stresses situated near $450 \mathrm{MPa}$ (i.e., $2250 \mathrm{~N} /$ wire) with a maximal deformation close to $7.5 \%$. The study of temperature effects associated to self-heating (see, for instance, ref. [6]) for the expected working frequencies in earthquake mitigation (about $1 \mathrm{~Hz}$ ) suggest that the deformation does not overcome 3 or $4 \%$. In fact, the maximal deformation was similar to the established for the $\mathrm{CuAlBe}$ alloy.
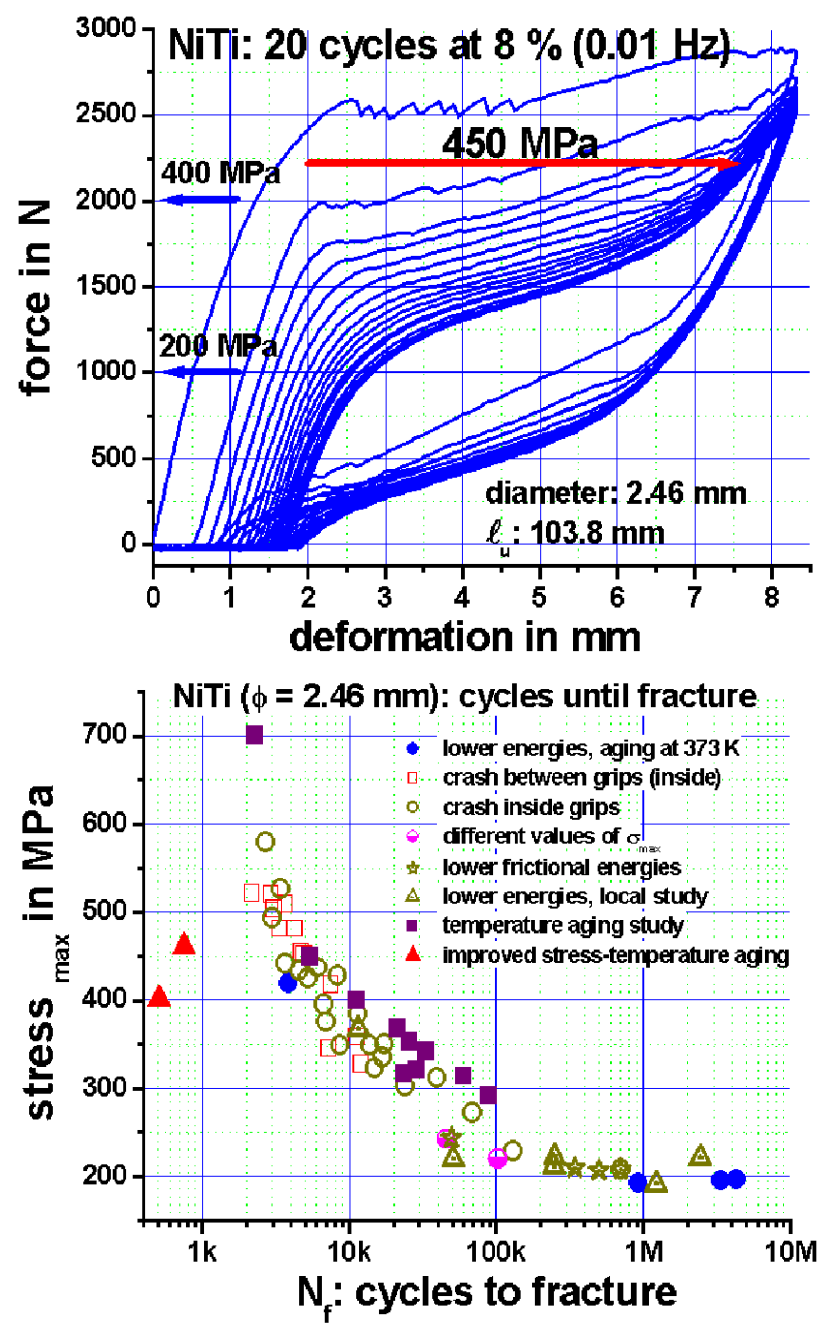

Figure 1. Experimental behavior of the NiTi alloy. Left: 20 cycles at $0.01 \mathrm{~Hz}$ with a deformation up to $8 \%$. Right: Study of the fracture-life for the NiTi alloy.

\section{Realistic test in a portico}

The test of the SMA behavior was carried out in a "shaking table" in 1-dimension (see Fig. 2 left). The portico, in steel (beam: HEM-120 of $4.10 \mathrm{~m}$, pillars: HEM-100 of $2.47 \mathrm{~m}$ ), and the lateral protections are built by TAMANSA (08050 Gavà, Catalonia, Spain). The portico is mounted over a chariot with 10 wheels moving inside two U-shape guidelines and was protected by supplementary reinforced walls for "out-of-plane" oscillations. To facilitate and ensuring that the portico movements are in-plane several wheels were situated: four wheels in bottom and four in the portico top. The inverted U-shape of the portico is established by 3 HEB elements, two (the pillars) with $2.47 \mathrm{~m}$ length and $100 \times 100 \mathrm{~mm}$ and one (the beam) with $4.10 \mathrm{~m}$ length and $120 \times 120 \mathrm{~m}$. In the upper side of the beam a series of transverse elements permits to situate up to 4 loaded boxes. One 
hydraulic system moves the chariot in back and forth sinusoidal displacements. Two inverted Vshaped were fixed to the chariot allowing a direct measurement of the beam net displacement relative to the bottom. One end of LVDT-HBM sensor was fixed in the V-shaped and the other end of LVDT (the end of moving element) was fixed in the bottom of the portico beam. Loading the boxes (up to 4) at the top of the portico beam to increase the load requires the available displacement facilities (overhead crane) in the C1-Laboratory - "Lab. de Construcció", UPC).

The maximum load used over the portico is close to $2000 \mathrm{~kg}$. One reference wall of concrete blocks is used for reference in the actuator displacing the chariot - portico device. The SMA dampers (two wires of $700 \mathrm{~mm}$, see, Fig. 2 right) were installed in the portico diagonals and joined to the frame with steel cables. In the outlined example, the actuator induces nominal accelerations of $0.8 \mathrm{~m} / \mathrm{s}^{2}$ and creates oscillations of 2 or $3 \mathrm{~Hz}$ (near $3.6 \mathrm{~m} / \mathrm{s}^{2}$ ) at the portico resonances (unloaded vs. loaded portico). The effective accelerations are similar to the higher "EL CENTRO" accelerations.

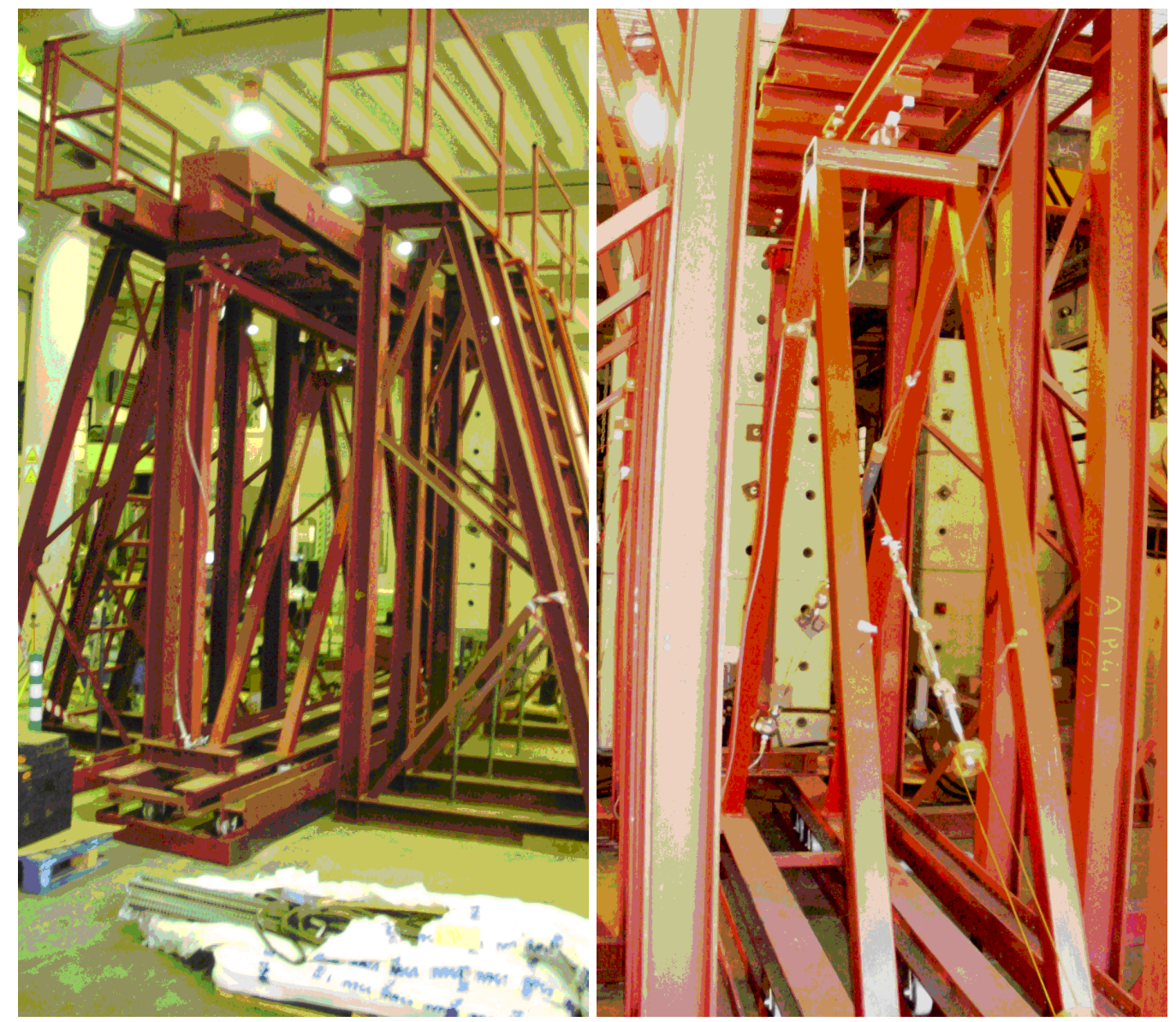

Figure 2. Left: The portico used to study the damping effect of SMA damper, the figure shows the lateral protections that avoid the out-of-plane oscillations. Right: The SMA dampers were situated in the portico diagonals and completed by steel wires. The reaction wall for the hydraulic piston is situated in the portico rear.

\section{Portico 1: The CuAlBe alloy}

The excitation by the actuator at $1 \mathrm{~Hz}$ with sinusoidal shape at lower amplitude (oscillation peak to peak of $\pm 5 \mathrm{~mm}$ ) and without upper boxes induces other harmonic frequencies, for instance, $3 \mathrm{~Hz}$, as shows the FFT (Fast Fourier Transform) in Fig. 3 Right. The use of SMA dampers (as shown in Fig. 2 Right) at this reduced excitation amplitude produces a drastic reduction of the oscillation amplitudes in the portico beam. The SMA wires were submitted to a light pre-stress. The applied force to the two wires $1.13 \mathrm{kN}$. In this case, with zero boxes over the beam, the deformation and their associated stress not overcome the stress required to induce the phase transition in the SMA 
wires. In fact, the analysis associate to the deformation of SMA wires shows that not mechanical energy is transformed in heat. The SMA dampers ( 2 wires of CuAlBe) work as two "braces" at low stress (near $2 \times 1.2 \mathrm{kN}$ ) and the intrinsic portico beam oscillations were, practically, suppressed. The carriage and the portico oscillate practically in phase under the action of the external actuator.

In Fig. 4, the four boxes (global load near $2000 \mathrm{~kg}$ ) are situated on the top of the portico beam and the actuator realizes 40 sinusoidal oscillations at $1 \mathrm{~Hz}$ and $\pm 15 \mathrm{~mm}$. The portico realizes larger oscillations $\pm 10 \mathrm{~mm}$ in comparison with the precedent example $( \pm 1.3 \mathrm{~mm})$. Without SMA the beam shows 1.0, 1.7 and $2 \mathrm{~Hz}$ as shows the Fig. 4 right. As expected, increasing the load on the portico the frequencies values were reduced. When SMA damper was introduced with a pre-stress force of $1.38 \mathrm{kN}$, the oscillation amplitude reduces to near the $40 \%$, and the frequency spectrum is extremely reduced. In this case, the absorbed energy for the SMA corresponding to all oscillation time and transformed in heat is the $121 \mathrm{~J}$.
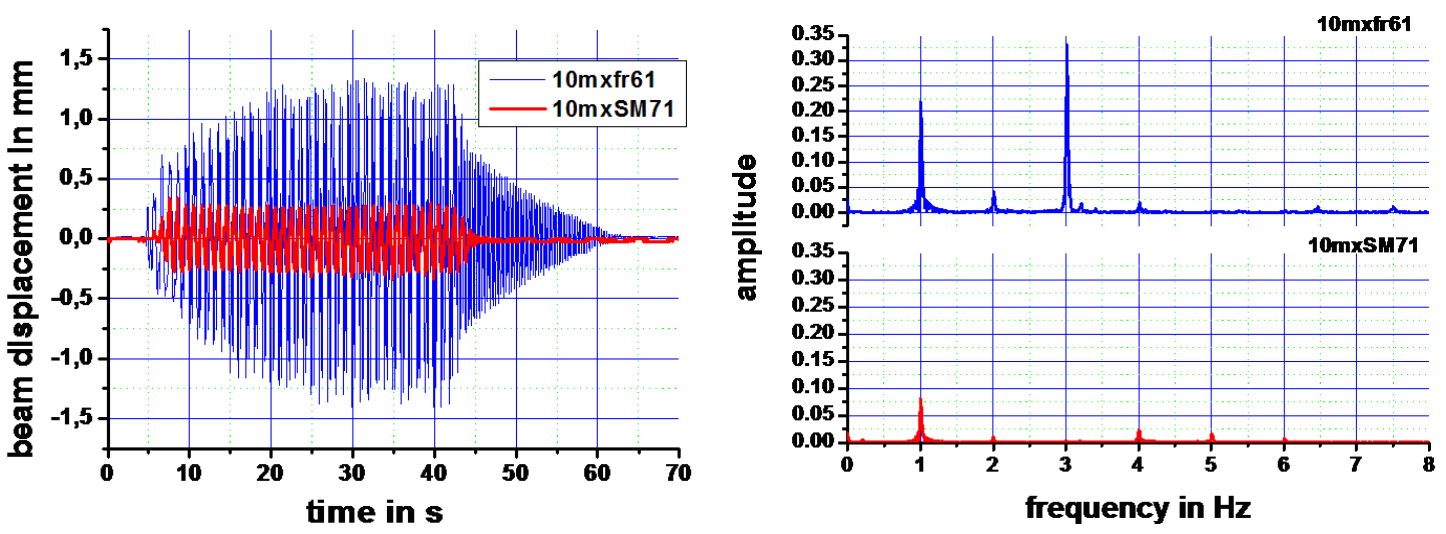

Figure 3. Experimental results using the actuator to one excitation frequency of $1 \mathrm{~Hz}$ and excitation amplitude peak to peak of $10 \mathrm{~mm}$. The supplementary load is zero or zero boxes in the upper portico. Left: free oscillations without dampers compared with the oscillations with SMA dampers (core). Right: Fourier transform of the beam displacements. Up: without SMA, Bottom: with SMA.
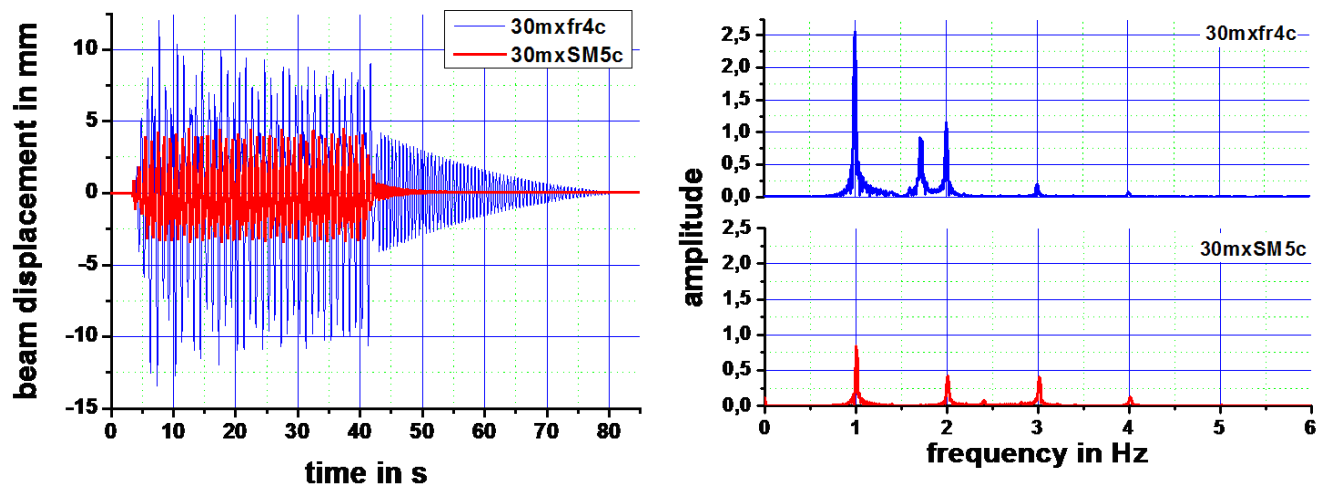

Figure 4. Experimental results using the actuator at one excitation frequency of $1 \mathrm{~Hz}$ and amplitude peak to peak of $30 \mathrm{~mm}$ and full available load. Left: free oscillations without dampers compared with the oscillations with SMA dampers (core). Right: Fourier transform of the beam displacements. Up: without SMA, Bottom: with SMA.

\section{Portico 2: The NiTi alloy}

Tests realized with NiTi show similar experimental results (Fig. 5). In fact, the two used wires in each damper produce similar forces and deformations for each damper. 

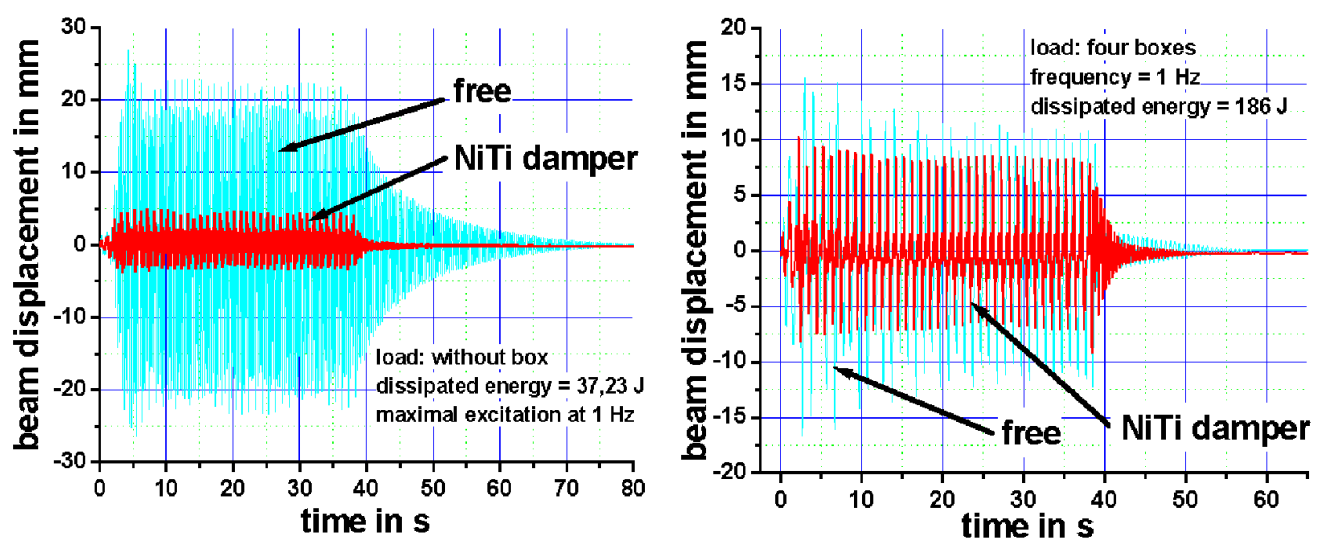

Figure 5. Damping by NiTi. Left: Without boxes. Right: full load (four boxes).

The action of NiTi damper (Fig. 5) is similar that the CuAlBe damper (Fig. 3 and 4). For lower load the dampers increase the strength of the portico and for higher load starts the transfer of mechanical energy to heat. In the study, the efficiency of the actuator (the hydraulic system) was reduced and the induced oscillations at one $\mathrm{Hz}$ cannot track the expected (in fact, the required) oscillation amplitude in the portico.

\section{Technical approach}

From the experimental analysis, the damper requires two adjusting parameters related to residual amplitude after damping (x) and the stress (force) in the damper. For the first one, it's required that the length of the damper ( ) satisfies the: $0.03=x(\mathrm{CuAlBe})$.

For the second one, the number of SMA wires $(\mathrm{N})$ in each damper was associated to dynamical forces $(\mathrm{F})$ in the beam to be damped in comparison with the reference forces $\left(\mathrm{F}^{\prime}{ }_{\mathrm{ref}}\right)$ in the examples studied: $\mathrm{N} \approx 2 \mathrm{~F} / \mathrm{F}^{\prime}{ }_{\text {ref }} \approx 2 \mathrm{~F} / 20 \mathrm{kN}$.

\section{Summary}

The study of CuAlBe shows that, for applications as dampers to mitigate earthquakes in light structures, CuAlBe is as good as NiTi when, in working, the maximal practical deformation of SMA remain near $3 \%$. The study of NiTi establishes that the alloy overcomes the requirements in fracture-life and in available deformation. The results obtained with the portico tests with dampers in the diagonals establish the classical decrease of the portico resonance frequency with the load and, also, the positive damping effects of the SMA. The portico measurements found that SMA dampers using CuAlBe as well as using NiTi reduces the oscillation amplitude to less than a half.

\section{Acknowledgements}

To Jordi Lafuente Civil Eng. School, UPC, for your decisive support in the portico measurements. The Spanish project "M. Formento", C22/06 is gratefully acknowledged. The support by the M.L1. Perea (civil eng.) in the portico preparation is, also, acknowledged.

\section{References}

[1] V. Torra, A. Isalgue, F. Martorell, F. C. Lovey and Patrick Terriault, "Damping in Civil Engineering using SMA. Part I: Particular Properties of CuAlBe for Damping of Family Houses": Can. Metall. Quart., Vol. 49(2), (2010), pp. 179-190

[2] A. Isalgue, V. Torra, G. Carreras, C. Auguet and F.C. Lovey, "SMA smart materials (CuAlBe and NiTi) for use in damping: the implications of reliability for long time applications and aging behavior": Proceedings of the Smart Structural Systems Technologies (S(3) $\mathrm{T}^{2010}$ ), Porto, Portugal, 6-9 April 2010, pp. 471-481. ISBN: 978-989-96697-0-3 
[3] Y.F. Zhang, J.A. Camilleri and S.Y. Zhu, "Mechanical properties of superelastic Cu-Al-Be wires at cold temperatures for the seismic protection of bridges": Smart Materials \& Structures Vol. 17 (2) (2008), Article Number: 025008

[4] A. Isalgue, V. Torra, A. Yawny and F.C. Lovey, "Metastable effects on martensitic transformation in SMA Part VI. The Clausius-Clapeyron relationship": J. Therm. Anal. Calorim. Vol. 91 (3) (2008), pp. 991-998

[5] G. Carreras, A. Isalgue, V. Torra, F. C. Lovey and H. Soul, "Metastable effects on martensitic transformation in SMA Part V. Fatigue-life and detailed hysteresis behavior in NiTi and Cu-based alloy": J. Therm. Anal. Calorim. Vol. 91 (2) (2007), pp. 575-579

[6] V. Torra, A. Isalgue, C. Auguet, G. Carreras, F.C. Lovey, P. Terriault, "Damping in Civil Engineering using SMA. Part II. Particular properties of NiTi for damping of stayed cables in bridges": submitted to Can. Metall. Quart. (2010) 